\title{
Method for structural optimization of avionics of unmanned aerial vehicle
}

\author{
Pashchuk Yu. M. ${ }^{1}$, Salnyk Yu. P. ${ }^{1}$, Pashkovskyi V. V. ${ }^{1}$, \\ Zaiets Ya. H. ${ }^{1}$, Miskiv V.-M. V. ${ }^{2}$, Shkiliuk O. P. ${ }^{2}$ \\ ${ }^{1}$ National Army Academy, \\ 32 Heroes of Maidan Str., 79012, Lviv, Ukraine \\ ${ }^{2}$ Lviv Polytechnic National University, \\ 12 S. Bandera Str., 79013, Lviv, Ukraine
}

(Received 12 February 2020; Revised 3 September 2020; Accepted 5 September 2020)

\begin{abstract}
This paper presents an approach for identifying the optimal configuration of avionic systems of the unmanned aerial vehicle (UAV) based on an additive multi-attribute utility function. The function arguments are technical and economic indicators of avionics design quality that are specified in accordance with the UAV requirements. The method is developed on an improved decision model that has a high degree of adequacy primarily by the increasing number of the utility attributes and using advanced reliability models of avionic systems. These reliability models consider in addition to the reliability parameters of main and standby elements of fault-tolerant units the effectiveness of non-perfect detection and switching devices. The proposed method enables the increasing certainty of design analysis results. It allows determining the optimal configurations of the avionic systems and rational maintenance regime ensuring needed effectiveness and reliability, minimizing the expenditure of resources.
\end{abstract}

Keywords: unmanned aerial vehicle, avionics, structural design optimization, reliability, redundancy, maintenance.

2010 MSC: 93B50, 93B51, 49N99

DOI: $10.23939 / \mathrm{mmc} 2020.02 .373$

\section{Introduction}

The experience of armed conflicts for the past twenty years shows that unmanned aerial vehicles (UAV) play a growing role in obtaining intelligence data to enhance situation awareness and performing other important tasks. The UAV effectiveness strongly depends on their reliability due to the continual increase of intensity of unmanned aircraft employment, widening range of operating conditions, and growing avionics complexity [1,2]. The increasing level of avionics sophistication causes additional reliability problems that demand more complex solutions [3]. The reliability of avionic systems is especially important when a line-of-sight link with control stations is absent or the enemy uses electronic countermeasures equipment.

The required avionics reliability is formed at the early design stages and can be realized primarily using fault tolerance, fault avoidance and forming expedient maintenance strategies and modes [1-5]. Applying these principles engineers should consider achieving all ranges of numerous conflicting objectives under uncertainty of decision outcomes [6-13]. In this sense, designers need to assess the versatile value trade-offs meeting acceptable avionics weight, size, power consumption, overall cost, other engineering characteristics and lifecycle performances. All above-mentioned factors comprehensively affect choosing the optimal avionic systems configurations among many alternatives [14-17].

Such complex design analysis problems are commonly solved in the frame of Utility Theory and Decision Theory using various design methodologies with formal analysis, namely the Set-Based Design, Value Driven Design and Multi-Attribute Utility Analysis [6-17]. The existed corresponding techniques for implementing the UAV avionics structural optimization [14-17] have both considerable capabilities 
and certain limitations. The main constraint of these methods lies in applying simplified formal decision-making models and downsizing the sets of multidisciplinary values. Furthermore, to estimate reliability and find an optimal avionics design, decision-makers usually do not consider maintenance regimes (MR) and use mainly simplified reliability models for various types of redundancy with the assumption of perfect detection and switching devices (DSD) $[1,3-5,19]$.

In the frame of accepted maintenance strategy, the different MR vary with frequency and volume of preventive and repair maintenance (PRM) activities, in particular periodic maintenance inspection (PMI) [1, 19-21]. The PMI is divided into operational (preflight and postflight) and scheduled maintenance $[20,21]$. Choosing for avionics the most preferred MR affects the strength and qualification of unmanned aircraft system (UAS) maintenance personnel, UAV operating and support costs, availability, and other characteristics [19,21].

Using the simplified reliability models for redundancy amount calculation often causes lowering the field reliability of avionics below the expected level $[1,3-5,19]$. Reliability of fault-tolerant units (FTU) depends not only on the reliability of their main and standby elements, redundancy techniques and amount of redundancy. Furthermore, it is affected by the effectiveness of equipment, which detects faults, diagnoses and isolates them, reconfigures such units $[3-5,16,19]$. As avionic systems typically have a large amount of structural redundancy, there is a necessity for applying improved reliability models considering the effectiveness of non-perfect DSD.

Thus, the aim of this article is to improve the known methods for optimizing UAV avionics structure ensuring needed effectiveness and reliability, considering the rational MR and minimizing the expenditure of resources. Development of the proposed methodology involves:

1) building a formal decision model with high adequacy;

2) developing of an optimality criterion and optimization constraints;

3) formulation of an optimization task;

4) building an algorithm for solving the optimization task.

\section{Developing the decision model for UAV avionics structural optimization}

Developing the decision model is divided into three main steps:

1) multivariate analysis of factors influencing the UAV avionics design;

2) forming a vector of utility attributes;

3) selecting an optimization method.

\subsection{Multivariate analysis of factors influencing the UAV avionics design}

The UAV avionics design is primarily oriented to achieve required combat effectiveness which is determined by the degree of unmanned aircraft adaptation to perform its main functions. Since most UAVs are designed for surveillance and reconnaissance, the unmanned aircraft effectiveness can be determined as a target task performance metric [22] from the formula:

$$
P_{E}(t)=\left\{P_{D}(t), P_{C}(t), P_{R}(t), P_{U A V}(t), \ldots\right\},
$$

where $P_{D}(t), P_{C}(t), P_{R}(t)$ and $P_{U A V}(t)$ are probabilities of detection, classification, recognition of targets, and UAV reliability.

The UAV effectiveness is characterized by other metrics, for instance, by flight time $T_{F}$, which depends on the unmanned aircraft performances, combat tasks, weather conditions and other factors. Total flight times of the UAV in supporting military operation over $D_{O}$ days with combat intensity $k_{C I}$ defines a period of the unmanned aircraft employment cycle $T_{E C}$ from the formula:

$$
T_{E C}=T_{F} D_{O} k_{C I}
$$


The unmanned aircraft effectiveness depends primarily on its characteristics, in particular on the UAV and avionics reliability. One of the main ways to increase avionic systems reliability as well as reduce frequency and volume of PMI activities is to introduce redundancy to these systems $[16,19,21]$. As a result of this approach, avionics is operated in the failure-free (automatic self-recovery) mode without performing repair maintenance over the UAV employment cycle [23-25]. In this case, during the operational maintenance and UAV flights, only operation state of the main FTU elements is monitored. So, the failures of the main and standby FTU elements may be considered respectively as evident and latent failures [5,23-25].

On the other hand, insufficient reliability of avionics without using addition of redundancy requires performing the PRM of avionic systems after each UAV flight. If we choose two contrasting (corresponding) maintenance regimes with intervals between the PRM activities $T_{M 1}$ for the $1^{\text {st }} \mathrm{MR}$ and $T_{M 2}$ for the $2^{\text {nd }} \mathrm{MR}$, the avionics failure probability $Q_{A}(t)$ can be represented for these modes accordingly by the graphs $Q_{A 1}(t)$ and $Q_{A 2}(t)$ (see Fig. 1 ).

To implement the $1^{\text {st }}$ MR, the UAS units should be staffed with highly skilled maintenance specialists that have appropriate education and training for performing complex PRM activities. This approach allows minimizing time of the UAV withdrawal from operation. On the other hand, it makes increasing of operating and support costs, and lowering mobility of the UAS units [19].

Using addition of redundancy of avionics improves its reliability and enables adjusting the frequency of PRM activities, for example, by increasing period between them to the required value $T_{M 2}$. This interval corresponds to appropriate number of UAV launches with total flights time that is longer or equal to the period between the

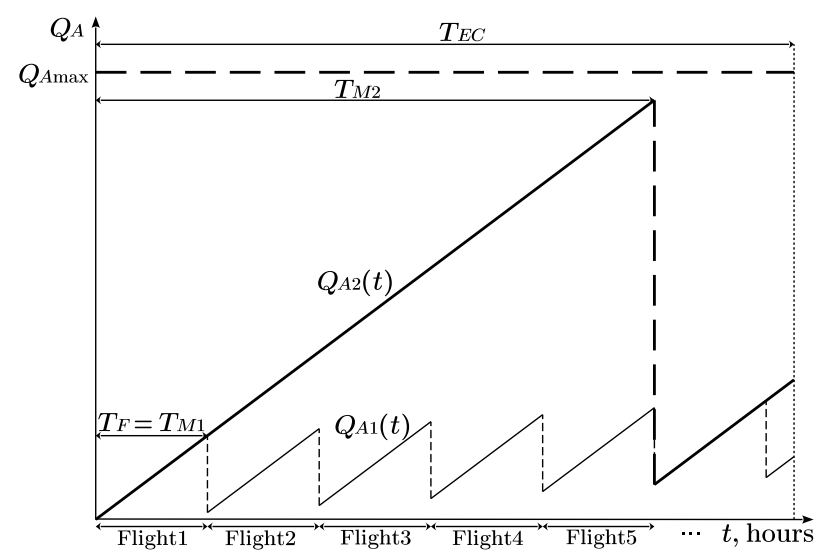

Fig. 1. Graphs of avionics failure probability: $Q_{A 1}(t)$ for the $1^{s t}$ maintenance regime and $Q_{A 2}(t)$ for the $2^{\text {nd }}$ maintenance regime. scheduled maintenance activities. Respectively, the $2^{\text {nd }} \mathrm{MR}$ application results in using automatic self-recovery function for avionic systems and performing only operational maintenance. To implement the $2^{\text {nd }} \mathrm{MR}$, it is rational to create the centralized maintenance workshops in the area of operation for supporting several UAS units. This leads to extending time of the UAVs withdrawal from operation and reducing their availability. Time that required for PRM of avionics should be added to the times of unmanned aircraft delivery to workshop and return to UAS unit, or to the time for transporting maintenance teams to UAS units. Besides, it should be considered the time for staying UAVs in the line for needed PRM. In addition to achieving the required avionics reliability, use of the $2^{\text {nd }} \mathrm{MR}$ allows increasing the UAS mobility by saving human, technical and economic resources that are involved in the PRM during the UAV employment cycle. However, these advantages are followed by increasing the avionics complexity, weight, size and power consumption, as well as, design cost.

Based on analysis of the current state and trends of the UAV avionics development, the following main four types of FTUs should be considered for ensuring required reliability [2,3,16,19]: bimodal parallel; bimodal series; three component redundancy, and $k$-out-of- $n$ majority voting redundancy, in particular 2-out-of-3 systems with inherent standby elements. Most of the known reliability models for these types of hardware redundancy are obtained with assumption of using perfect DSD [3-5,19]. Therefore, for more accurate estimation of avionics reliability there is a need to use reliability models for the selected FTUs considering effectiveness of non-perfect DSD. Derived from the evaluation of existing methods for building such models, Markov method and modified space states technology were applied [19]. The paper [19] presents improved reliability models of the FTUs that unlike known models take into account of the DSD parameters besides reliability parameters of main and standby FTU elements. Using of these models enables increasing validity of reliability evaluation. 
To improve the unmanned aircraft effectiveness, particularly increase their reliability and extend the period of UAV employment cycle, it is crucial to solve another conflicting problem. First of all, designers should meet the minimum expenditure of technical (weight, size and power consumption) and economic resources $[15,16,19]$. For military unmanned aircraft to achieve the needed technical characteristics is a dominant design objective comparatively to costs saving. The avionics weight is considered as a key parameter that reflects its design quality. Even its slight reduce allows increasing, for instance, the unmanned aircraft flight times, duration of the UAVs employment cycle, and accordingly their effectiveness. The UAV takeoff weight is defined from the weight balance equation (3) and formula (4) [26]:

$$
\begin{aligned}
m_{U A V} & =m_{A F}+m_{P P}+m_{A S}+m_{P L}+m_{F}, \\
1 & =\bar{m}_{A F}+\bar{m}_{P P}+\bar{m}_{A S}+\bar{m}_{P L}+\bar{m}_{F},
\end{aligned}
$$

where $m_{A F}, m_{P P}, m_{A S}, m_{P L}$ and $m_{F}$ are respectively weight of the UAV airframe, powerplant, avionics, payload and fuel, and $\bar{m}_{A F}, \bar{m}_{P P}, \bar{m}_{A S}, \bar{m}_{P L}, \bar{m}_{F}$ are normalized values of the above mentioned parameters.

Recent progress in the avionic systems enables optimization of their structure considering only weight and power consumption, as main technical indices, and disregarding their size.

According to the major principles of systems design, decision makers should diminish the overall cost of avionics that includes costs of design, engineering, and procurement, as well as operating, support and other costs $[3,6,19,27]$. Since military unmanned aircraft do not generate profit, it is appropriate to consider the overall avionics cost as the main economic metric for assessing its efficiency design. This metric includes the UAV design, manufacturing and maintenance costs. Usually a ratio of these costs is approximately equal to $1: 2.5: 3[27]$.

Hence, after structuring the main objectives of avionics design we are able to build their hierarchy with the UAV combat effectiveness at the top.

\subsection{Forming the vector of utility attributes}

To compete design analysis engineers usually use the following formal equation [28]:

$$
D=\left\{Y, Q_{S}, K, Q_{K}\right\},
$$

where $D$ is set of input data; $Y=\left\{Y_{1}, \ldots, Y_{p}\right\}$ is set of conditions; $Q_{S}=\left\{Q_{S 1}, \ldots, Q_{S q}\right\}$ is set of constrains on developing avionics structure; $K=\left\{K_{1}, \ldots, K_{m}\right\}$ is set (vector) of utility attributes $Q_{K}=\left\{Q_{K 1}, \ldots, Q_{K r}\right\}$ is set of constrains on applying utility attributes.

Avionic systems configurations, which match the set of conditions $Y$, are deter-mined as acceptable variants, and configurations that also correspond to the set of input data $D$ are strictly acceptable [28]. A design among all strictly acceptable variants, which ensures the best value of vector $K$, is optimal. The assessment is provided according to pre-selected rule (optimality criteria), on the basis of which one value of the vector $K$ should be considered better (worse) than other values [28]. In this context, the optimal variant has the maximum expected utility [7-11].

Based on results of the above-mentioned analysis of factors, we can define the main utility attributes specifying the set of multidisciplinary values and building their hierarchy. Thus, the set of utility attributes includes the following incommensurable components that characterize various aspects of the $\mathrm{UAV}$ and its avionics design:

1) unmanned aircraft effectiveness $P_{E}(t)$;

2) UAV reliability $P_{U A V}(t)$;

3) flight time $T_{F}$;

4) period of the unmanned aircraft employment cycle $T_{E C}$;

5) interval between the PRM activities $T_{M}$;

6) reliability of avionics components;

Mathematical Modeling and Computing, Vol. 7, No. 2, pp. 373-388 (2020) 
7) technical (weight and power consumption) and economic (overall avionics cost that includes design, manufacturing and maintenance costs) indices for each avionic system.

The proposed multidimensional set of utility attributes is considered as the basis of improved decision model for identifying the optimal avionics structure. Unlike the known models it has a higher degree of adequacy primarily by increasing number of the utility attributes and using the refined avionics reliability models.

\subsection{Rationale of selecting the optimization method}

Based on analysis of known optimization methodologies [3,6-17], to solve the problem of optimizing the avionics structure we propose to apply a multi-criteria decision analysis method that is based on use of the additive multi-attribute utility function $[8,28]$. This approach enables the multidisciplinary assessment of avionics design concepts and finding the preferred variant with the highest multi-attribute utility. The method has the following practical advantages:

1) time-tested mathematical tools;

2) linear dependence of partial utility functions that enables increasing the number of arguments and allows considering the priority of different attributes depending on the decision-makers' preferences, technical design specifications and other factors;

3) allows integrating of costs assessment for different kinds of resources expenditure in order to reach the maximum expected utility;

4) enables minimizing time for providing calculations in support of making rational decisions at the early design stages.

However, the efficiency of the above stated approach relies on the experts' experience knowledge and professional judgements as well as on their subjective assessment of different alternatives and possible consequences. Furthermore, this method involves building the resulting multi-attribute utility function that involves $[8,28]$ :

1) determination of the importance of each attribute;

2) identification of the main utility attributes and their importance weights;

3) defining of corresponding quantified constraints;

4) development of appropriate analytical model of optimality criterion.

\section{Developing the optimality criterion and optimization constraints}

The UAV avionics contains three main components [1, 19,20]:

1) flight control system (FCS):

- navigation subsystem;

- flight computer;

- autopilot;

2) communications system (CS);

3) flight management system (FMS):

- electrical power supply subsystem;

- powerplant;

- airframe;

- fuel;

- different sensors.

All these avionic systems are functionally independent, so the task of optimizing their configurations may be solved one after another.

The selected optimization approach stipulates differentiation of components of the vector of utility attributes into two groups according to their hierarchy in compliance with the "design objectives tree": 
1) dominated partial optimality criteria that reflect the most significant design goals and have obvious advantages (preferences);

2) attributes that are used as constraints.

Since in practice the field reliability of the UAV avionic systems and respectively the UAV effectiveness do not meet the requirements $[1,19]$, the priority in the avionics design is to achieve the needed reliability and period of the UAV employment cycle. These terms are represented by the following expressions:

$$
\begin{gathered}
T_{E C} \geqslant T_{E C m i n}, \\
P_{U A V}\left(T_{0}=T_{E C m i n}\right) \geqslant P_{U A V m i n}, \\
P_{F C S}\left(T_{0}=T_{E C m i n}\right) \geqslant P_{F C S m i n}, \\
P_{C S}\left(T_{0}=T_{E C m i n}\right) \geqslant P_{C S m i n}, \\
P_{F M S}\left(T_{0}=T_{E C m i n}\right) \geqslant P_{F M S m i n},
\end{gathered}
$$

where $T_{E C \min }$ is minimum value of period of the UAV employment cycle; $P_{U A V \min }, P_{F C S m i n}, P_{C S m i n}$ and $P_{F M S m i n}$ are minimum values of reliability accordingly for unmanned aerial vehicle, flight control system, communications system and flight management system.

To implement the above stated requirements, first of all, we propose to identify the rational configurations of avionic systems based on the results of their reliability calculations using the improved reliability models and considering the maintenance regimes.

Thus, for each $i(i \in 1, \ldots, r)$ maintenance regime, which is determined by the operation interval $T_{M i}$ (Table 1$)$, three sets of rational fault-tolerant configurations for avionic systems are formed accordingly: for FCS $N_{1 i}\left(1, \ldots, n_{1 i}\right)$; for CS $N_{2 i}\left(1, \ldots, n_{2 i}\right)$; for $\operatorname{FMS~} N_{3 i}\left(1, \ldots, n_{3 i}\right)$.

Table 1. Sets of rational configurations of avionic systems based on their reliability assessment considering maintenance regimes.

\begin{tabular}{|c|c|c|c|c|}
\hline \multirow{2}{*}{$\begin{array}{c}\text { Number } \\
\text { of MR }\end{array}$} & \multirow{2}{*}{$\begin{array}{c}\text { Maintenance } \\
\text { interval }\end{array}$} & \multicolumn{3}{|c|}{$\begin{array}{c}\text { Sets of rational configurations of avionic systems } \\
\text { based on their reliability assessment }\end{array}$} \\
\cline { 3 - 5 } & & $\begin{array}{c}\text { Flight control } \\
\text { system }\end{array}$ & $\begin{array}{c}\text { Communications } \\
\text { system }\end{array}$ & $\begin{array}{c}\text { Flight management } \\
\text { system }\end{array}$ \\
\hline 1 & $T_{M 1}$ & $N_{11}=\left\{1, \ldots, n_{11}\right\}$ & $N_{21}=\left\{1, \ldots, n_{21}\right\}$ & $N_{31}=\left\{1, \ldots, n_{31}\right\}$ \\
\hline 2 & $T_{M 2}$ & $N_{12}=\left\{1, \ldots, n_{12}\right\}$ & $N_{22}=\left\{1, \ldots, n_{22}\right\}$ & $N_{32}=\left\{1, \ldots, n_{32}\right\}$ \\
\hline$\ldots$ & $\ldots$ & $\ldots$ & $\ldots$ & $\ldots$ \\
\hline$r$ & $T_{M r}$ & $N_{1 r}=\left\{1, \ldots, n_{1 r}\right\}$ & $N_{2 r}=\left\{1, \ldots, n_{2 r}\right\}$ & $N_{3 r}=\left\{1, \ldots, n_{3 r}\right\}$ \\
\hline
\end{tabular}

The following denotations for three main components of avionics are given in the Table 1: for FCS $k=1 ; j \in 1, \ldots, n_{1 i} ;$ for CS $k=2, j \in 1, \ldots, n_{2 i}$; and for $\operatorname{FMS~} k=3 ; j \in 1, \ldots, n_{3 i}$.

Ensuring the constraints (6)-(10) requires reducing corresponding expenditure of technical and economic resources. According to the UAV technical design specifications the initial data for the avionics design are the maximum allowable values of avionics weight $\left(M_{1 \max } ; M_{2 \max } ; M_{3 \max }\right)$, power consumption $\left(S_{1 \max } ; S_{2 \max } ; S_{3 \max }\right)$ and overall cost $\left(V_{1 \max } ; V_{2 \max } ; V_{3 \max }\right)$ for FCS, CS and FMS respectively.

To form a generalized optimality criterion, which determines the properties of the best design decision with minimizing technical and economic costs, we propose to include the following independent arguments in the resulting multi-attribute utility function: $M_{k i j}$ is weight, $S_{k i j}$ is power consumption and $V_{k i j}$ is overall cost for $j$ configuration of $k$ avionic system considering $i$ maintenance regime.

According to the accepted optimization method the resulting utility function is presented in form of integrated index of resources expenditure:

$$
Z_{k i j}=\gamma_{1} \bar{M}_{k i j}+\gamma_{2} \bar{S}_{k i j}+\gamma_{3} \bar{V}_{k i j}
$$

Mathematical Modeling and Computing, Vol. 7, No. 2, pp. 373-388 (2020) 
where $\bar{M}_{k i j}=\frac{M_{k i j}}{M_{k m a x}}, \bar{S}_{k i j}=\frac{S_{k i j}}{S_{k m a x}}, \bar{V}_{k i j}=\frac{V_{k i j}}{V_{k m a x}}$ are utility functions of partial optimality criteria (weight, power consumption and overall cost), which are normalized from 0 to 1 and have agreed measurement scale [28]; $\gamma_{1}, \gamma_{2}, \gamma_{3}$ are weight coefficients accordingly for weight, power consumption and overall cost $\left(\gamma_{1}>0, \gamma_{2}>0, \gamma_{3}>0\right)$. These coefficients are normalized on the basis of developed hierarchical decision model depending on experts' professional judgements, knowledge and experience [8]:

$$
1=\gamma_{1}+\gamma_{2}+\gamma_{3}
$$

Usually designers choose the coefficients $\gamma_{1}, \gamma_{2}, \gamma_{3}$ based on heuristic methods in accordance with the specified requirements and other factors and commonly they consider the priority of the weight indicator $[2,3,8,14]$.

The above stated index (11) defines the expenditure of technical and economic resources for $j$ $\left(j \in 1, \ldots, n_{1 i} j \in 1, \ldots, n_{2 i} j \in 1, \ldots, n_{2 i}\right)$ configuration of $k(k \in 1,2,3)$ avionic system considering $i\left(i \in 1, \ldots, i_{r}\right)$ maintenance regime.

The minimum of technical and economic resources needed for avionics design when applying $i$ maintenance regime is determined from the formula:

$$
Z_{i}=Z_{1 i}+Z_{2 i}+Z_{3 i}
$$

where $Z_{k i}=\min Z_{k i j} \cdot(k \in 1,2,3)$ are minimum values (local minimums) of indices of resources expenditure for FCS, CS and FMS considering i maintenance regime. The optimal configurations of avionic systems and rational MR can be identified on the basis of comparing results $Z_{i}\left(i \in 1, \ldots, i_{r}\right)$ which are obtained for different maintenance regimes:

$$
Z=\min Z_{i}
$$

Thus, the generalized optimality criterion in the form of multilinear utility function is proposed to find the optimal variant of the avionics structure. The function arguments are technical and economic indicators of avionics design quality that are specified in accordance with the UAV requirements. The optimization constraints (6)-(10) include the minimum values of UAV reliability and reliability of avionics components; duration of the UAV employment cycle; as well as the maximum values of technical (weight and power consumption) and economic (overall cost) indices for avionic systems.

\section{Formulation of the optimization task}

In general, the multi-criteria problem of optimizing the avionics structure consists in determining the configurations of avionic systems, which correspond to the sets of conditions and input data (5). Furthermore, based on the selected optimality criterion these configurations must ensure the best value of the vector of utility attributes $K$. Solving the optimization problem separately for each avionic system involves:

1) forming possible configurations of avionic systems that match their reliability requirements considering $i \mathrm{MR}$ in the spaces of strictly acceptable variants $R_{k i}^{N}$ ( $R_{1 i}^{N}$ for FCS, $R_{2 i}^{N}$ for CS, $R_{3 i}^{N}$ for FMS), which are represented by the corresponding bounded sets of points $N_{1 i}, N_{2 i}, N_{3 i}$;

2) finding the points from sets $N_{1 i}, N_{2 i}, N_{3 i}$ that have the best values of the vectors $K_{1 i}, K_{2 i}, K_{3 i}$, respectively for FCS, CS and FMS, taking $i$ MR into account;

3) determining the optimal configurations of avionic systems that ensure the maxi-mum expected utility.

The illustrative examples of the resulting multilinear utility function

$$
Z_{11 j}=\gamma_{1} \bar{M}_{11 j}+\gamma_{2} \bar{S}_{11 j}+\gamma_{3} \bar{V}_{11 j}
$$

and its partial linear components are depicted in Fig. 2 and Fig. 3 accordingly. 


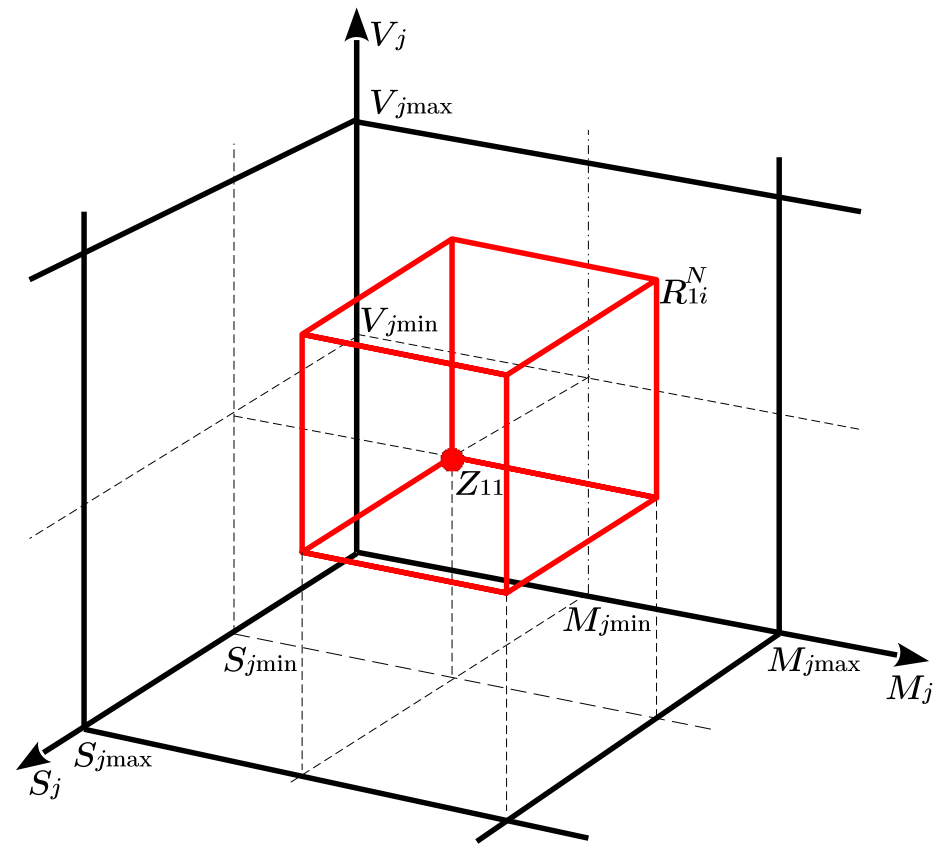

Fig. 2. Geometric interpretation of the multilinear utility function for the FCS considering the $1^{\text {st }}$ maintenance regime.

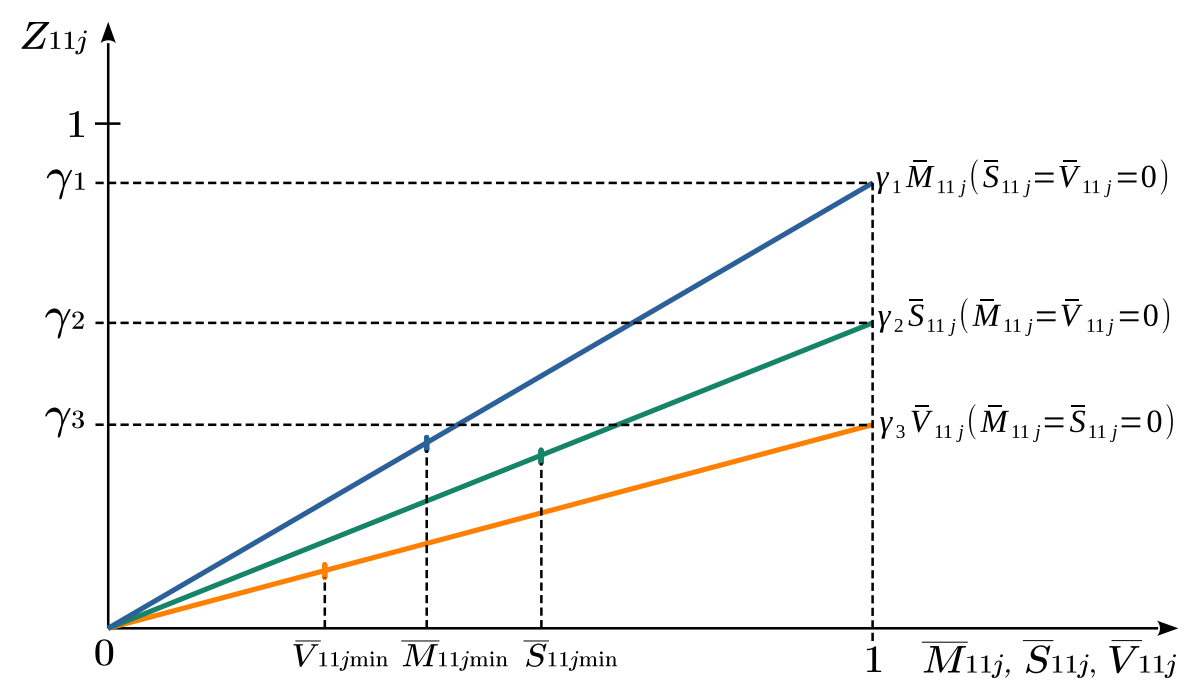

Fig. 3. Geometric interpretation of the partial utility functions for the FCS considering the $1^{\text {st }}$ maintenance regime.

dex (11) that have respectively the following minimum values:

$$
\begin{gathered}
M_{j \min }=\gamma_{1} \bar{M}_{11 \min }=\gamma_{1} \frac{M_{11 \min }}{M_{1 \max }} \\
S_{j \min }=\gamma_{2} \bar{S}_{11 \min }=\gamma_{2} \frac{S_{11 \min }}{S_{1 \max }} \\
V_{j \min }=\gamma_{3} \bar{V}_{11 \min }=\gamma_{3} \frac{V_{11 \min }}{V_{1 \max }}
\end{gathered}
$$

and maximum values:

$$
M_{j \max }=\gamma_{1} \bar{M}_{11 \max }=\gamma_{1} \frac{M_{11 \max }}{M_{1 \max }} \leqslant \gamma_{1}
$$

Mathematical Modeling and Computing, Vol. 7, No. 2, pp. 373-388 (2020)
The following denotations are used in these figures for $j\left(j \in 1, \ldots, n_{11}\right)$ configuration of flight control system $(k=1)$ considering $i$ maintenance regime $(i=1)$ :

$$
\begin{gathered}
\bar{M}_{11 j}=\frac{M_{11 j}}{M_{1 \max }}, \\
\bar{S}_{11 j}=\frac{S_{11 j}}{S_{1 \max }}, \\
\bar{V}_{11 j}=\frac{V_{11 j}}{V_{1 \max }}
\end{gathered}
$$

are utility functions of partial optimality criteria (weight, power consumption and overall cost), which are normalized from 0 to $1 ; Z_{11}$ is the minimum value of the resulting utility function; $R_{1 i}^{N}$ is the space, where the set of strictly acceptable configurations of FCS is formed under the terms of achieving required reliability and considering i MR;

$$
\begin{gathered}
M_{j}=\gamma_{1} \bar{M}_{11 j}=\frac{M_{11 j}}{M_{1 \max }}, \\
S_{j}=\gamma_{2} \bar{S}_{11 j}=\frac{S_{11 j}}{S_{1 \max }} \\
V_{j}=\gamma_{3} \bar{V}_{11 j}=\frac{V_{11 j}}{V_{1 \max }}
\end{gathered}
$$

are partial linear components of integrated in- 


$$
\begin{gathered}
S_{\text {jmax }}=\gamma_{2} \bar{S}_{11 \text { max }}=\gamma_{2} \frac{S_{11 \text { max }}}{S_{1 \text { max }}} \leqslant \gamma_{2} ; \\
V_{\text {jmax }}=\gamma_{3} \bar{V}_{11 \text { max }}=\gamma_{3} \frac{V_{11 \text { max }}}{V_{1 \text { max }}} \leqslant \gamma_{3} .
\end{gathered}
$$

Based on previous material we propose to use the developed criterion for identifying the optimal variant of the avionics structure ensuring the needed UAV effective-ness and reliability, complying with the resource constraints and considering MRs.

\section{Building the algorithm for solving the optimization task}

The above stated optimization task can be solved using the algorithm that is shown in Fig. 4. The algorithm is based on the dynamic programming method [29] and involves two main steps:

1) determination of the rational configurations of avionic systems under the terms of achieving required reliability and considering the maintenance regimes;

2) identification of the optimal variant of avionics structure and rational maintenance regime ensuring the needed UAV effectiveness and reliability, complying with the resource constraints.

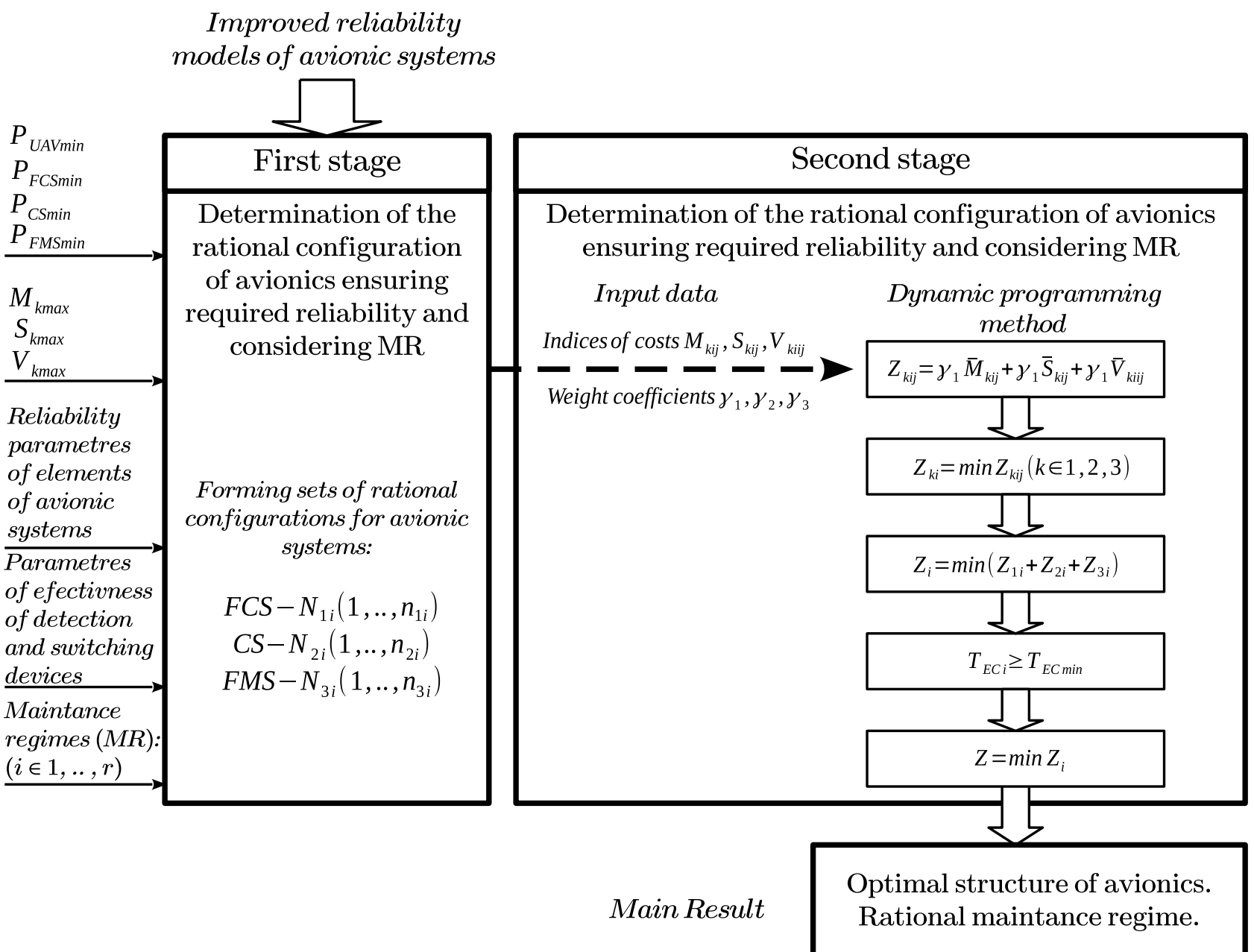

Fig. 4. Generalized algorithm for solving the optimization task.

The essence of the first stage of solving the optimization task lies in a multivariate analysis of possible configurations of the avionic systems and purposeful selection of reliability parameters of their components and elements ensuring required reliability and considering maintenance regimes.

Mathematical Modeling and Computing, Vol. 7, No. 2, pp. 373-388 (2020) 
Rational of selecting the expedient avionics configurations is performed step by step in ascending order (FTUs-subsystems-systems-avionics) considering the preformed set of maintenance regimes $R$ $(i \in 1, \ldots, r)$ based on the following assumptions:

1) the avionic systems and subsystems are considered as series components. A failure of such systems may be caused by a failure of any of their elements. For overall operability of these systems all their elements must be serviceable;

2) reliability parameters of the avionic systems and their elements are random variables having an exponential distribution.

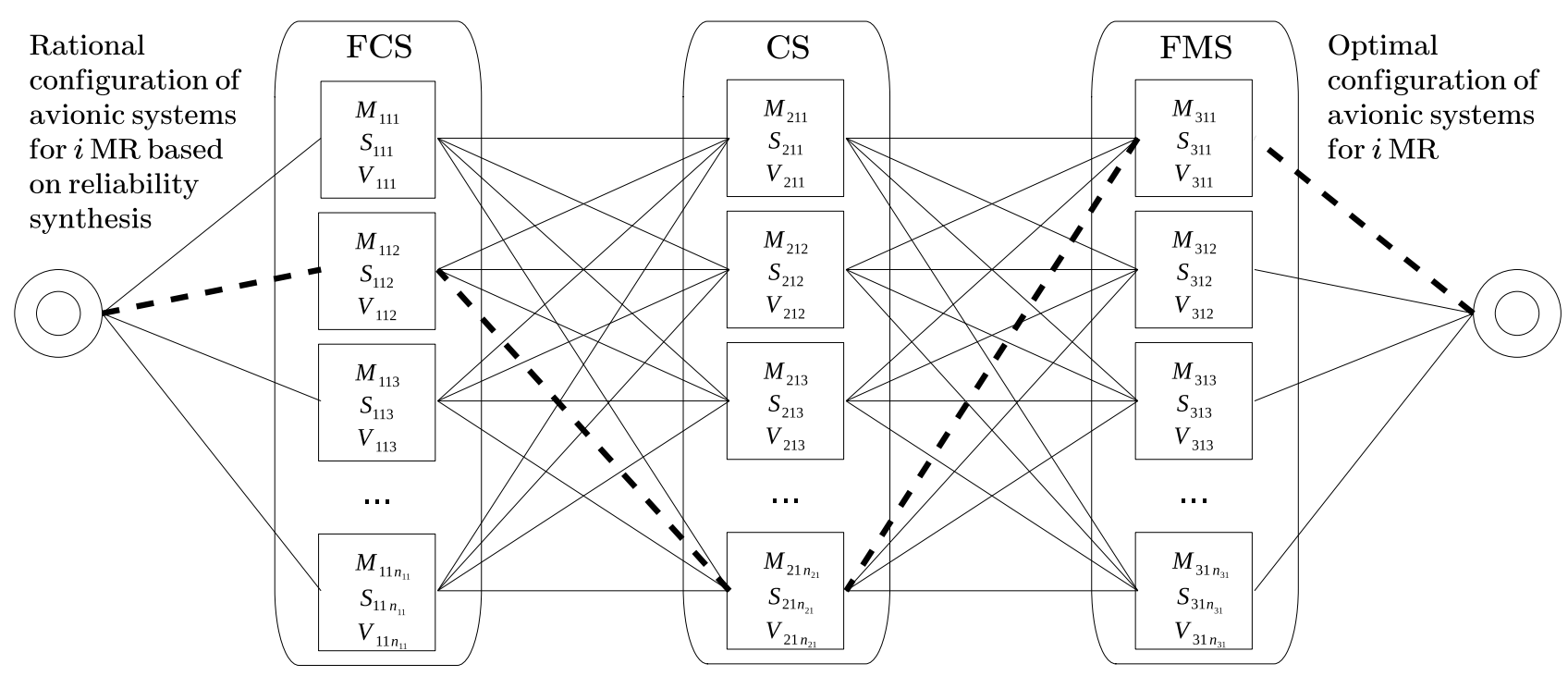

Fig. 5. Partial model for solving the $2^{n d}$ stage of the optimization task considering $i$ maintenance regime $(i=1)$.

Step 1. Building a formal model of solving the $2^{\text {nd }}$ stage of the optimization task based on the dynamic programming method. A part of this model considering $i \mathrm{MR}(i=1)$ is shown in Fig. 5 .

The formed sets of rational configurations for avionic systems considering $i$ MR (Table 1, Fig. 4) are the basic input data for incremental solving of the second stage of optimization task.

The main input data for solving the $2^{\text {nd }}$ stage of the optimization task are the indices of technical and economic costs for $j$ configuration of $k$ avionic system considering $i$ MR: weight $M_{k i j}$, power consumption $S_{k i j}$ and overall cost $V_{k i j}$.

Other input data are:

- design specifications - the maximum values of weight $\left(M_{1 \max } ; M_{2 \max } ; M_{3 \max }\right)$, power consumption $\left(S_{1 \max } ; S_{2 \max } ; S_{3 \max }\right)$ and overall cost $\left(V_{1 \max } ; V_{2 \max } ; V_{3 \max }\right)$ for FCS, CS and FMS respectively; - restrictions (6)-(10) that characterize the required period of the UAV employment cycle $T_{E C m i n}$, reliability of UAV $P_{U A V \min } \min$ and avionic systems $\left(P_{F C S m i n}, P_{C S m i n}, P_{F M S m i n}\right)$.

Step 2. Defining the weight coefficients of partial optimality criteria (weight, power consumption and overall cost) by decision makers with use of heuristic techniques based on their professional judgements, knowledge and experience [8,28].

Step 3. Calculation of values of resulting utility function (11) for $j$ configuration of $k$ avionic system considering $i$ maintenance regime with use of the dynamic programming method.

Step 4. Finding the local minimum values of indices of resources expenditure for avionic systems considering $i$ maintenance regime based on the formula (13).

Step 5. Identification of the optimal avionics structure and rational MR on the basis of comparing results $Z_{i}(i \in 1, \ldots, r)$ and finding among them the smallest value (14). In the case when some configurations, for example configurations $B_{1}$ and $B_{2}$, have the same value of indices $Z_{1}=Z_{2}$, then 
based on the priority of local optimality criteria the following in equations should be verified:

$$
\begin{aligned}
M\left(B_{1}\right) & <M\left(B_{1}\right), \\
S\left(B_{1}\right) & <S\left(B_{1}\right), \\
V\left(B_{1}\right) & <V\left(B_{1}\right),
\end{aligned}
$$

where $M\left(B_{1}\right), M\left(B_{2}\right), S\left(B_{1}\right), S\left(B_{2}\right), V\left(B_{1}\right), V\left(B_{2}\right)$ are weight, power consumption and overall cost of the configurations $B_{1}$ and $B_{2}$ respectively.

Based on the developed algorithm, the created prototypes of specialized software (ASNA-1, MathCad and Python) allow computerizing the procedures of design analysis that causes reducing the time to complete these operations and improving quality of decision-making process.

\section{Application of the developed optimization technique}

The application of the proposed optimization method is illustrated by the following example with next assumptions and limitations:

1) avionics reliability assessment is carried out after making design decisions which ensure achieving the main UAV performance characteristics [30];

2) reliability assessment of avionic systems includes evaluation of their hardware reliability and does not consider the reliability of avionics software and maintenance personnel [30];

3) preventive and repair maintenance is performed only by the UAS maintenance personnel who have proper training, qualification and certification;

4) avionic systems have a certain reliability level that allows the maintenance personnel do not perform the scheduled and repair maintenance during the UAV employment cycle;

5) cost of avionics maintenance is unchanged over all phases of the UAV life cycle.

We assume that the decision makers use the following input data according to the defined technical design specifications:

$-k$ avionic system $(k=1-F C S, k=2-C S, k=3-F M S)$;

- $i$ maintenance regime $(i \in 1, \ldots, r), T_{M 1}=50 \mathrm{hr}, T_{M 2}=100 \mathrm{hr}, T_{M 3}=200 \mathrm{hr}$;

- operation interval $T_{O P}=T_{E C m i n}=50 \mathrm{hr}, P_{U A V \min }(50)=0.93, P_{F C S m i n}(50)=0.983$, $P_{C \operatorname{Smin}}(50)=0.983, P_{F M S m i n}(50)=0.983$

- the maximum values of weight $\left(M_{1 \max }=0.75 \mathrm{~kg}, M_{2 \max }=0.4 \mathrm{~kg}, M_{3 \max }=0.98 \mathrm{~kg}\right)$, power consumption $\left(S_{1 \max }=0.36 \mathrm{~kW}, S_{2 \max }=0.4 \mathrm{~kW}, S_{3} \max =0.81 \mathrm{~kW}\right)$ and overall cost $\left(V_{1 \max }=\right.$ $\left.3.9 \cdot 10^{3} \$, V_{2 \max }=2.9 \cdot 10^{3} \$, V_{13 \max }=4.9 \cdot 10^{3} \$\right)$ for FCS, CS and FMS respectively;

$-\gamma_{1}=0.35, \gamma_{2}=0.33, \gamma_{3}=0.32$ (considering the priority of the weight index) $[2,3,8,14,18]$.

The $1^{\text {st }}$ stage of solving the optimization task is provided in the frame of reliability synthesis of avionic systems $[3,19,30]$ with use of the well-known and proposed reliability models of FTUs [19]:

- multivariate analysis of possible fault-tolerant configurations of the avionic systems;

- purposeful selection of reliability parameters of the avionics components ensuring required reliability and taking maintenance regimes into account;

- determination of the rational configurations of avionic systems.

Based on the accomplished calculations we can form the sets of rational configurations for avionic systems considering $i$ MR:

$$
N=\cup_{k, i=1}^{3} N_{k i}
$$

where $N_{k i}=\left\{1, \ldots, n_{k i}\right\}$ are subsets of rational configurations for avionic systems.

During the $2^{\text {nd }}$ stage of solving the optimization task we determine the values of weight $M_{k i j}$ [26], power consumption $S_{k i j}$ [31] and overall cost $V_{k i j}$ [27] for $j$ configuration of $k$ avionic system considering $i$ maintenance regime, as well as identify the values of resulting utility function $Z_{k i j}$ (Table 2). 
Table 2. Indices of resources expenditure for avionic systems considering $i \mathrm{MR}$.

\begin{tabular}{|c|c|c|c|c|c|}
\hline \multirow{2}{*}{$\begin{array}{l}\text { Number } \\
\text { of MR }\end{array}$} & \multirow{2}{*}{$\begin{array}{c}T_{M i}, \\
\mathrm{hr}\end{array}$} & \multirow{2}{*}{$\begin{array}{l}\text { Number of } \\
\text { configuration }\end{array}$} & \multicolumn{3}{|c|}{ Indices of resources expenditure } \\
\hline & & & $\overline{\mathrm{FCS}}(k=1)$ & $\mathrm{CS}(k=2)$ & $\overline{F M S}(k=3)$ \\
\hline \multirow{6}{*}{1} & \multirow{6}{*}{50} & 1 & $(0.55 ; 0.31 ; \underline{3.96})$ & $(0.32 ; 0.15 ; \underline{3.06})$ & $(0.79 ; 0.58 ; 4.89)$ \\
\hline & & & $Z_{111}=0.8675$ & $Z_{211}=0.7407$ & $Z_{311}=0.8527$ \\
\hline & & 2 & $(0.69 ; 0.31 ; 3.37)$ & $(0.36 ; 0.18 ; 2.83)$ & $(0.91 ; 0.73 ; 3.71)$ \\
\hline & & & $Z_{112}=0.8827$ & $Z_{212}=0.7757$ & $Z_{312}=0.8829$ \\
\hline & & 3 & $(0.67 ; 0.32 ; 3.55)$ & $(0.37 ; 0.19 ; 2.79)$ & $(0.93 ; 0.74 ; 3.07)$ \\
\hline & & & $Z_{113}=0.8972$ & $Z_{213}=0.9786$ & $Z_{313}=0.7818$ \\
\hline \multirow{6}{*}{2} & \multirow{6}{*}{100} & 4 & $(0.57 ; 0.28 ; 3.31)$ & $(0.34 ; 0.13 ; 2.15)$ & $(0.83 ; 0.59 ; 4.81)$ \\
\hline & & & $Z_{121}=\mathbf{0 . 7 9 4 3}$ & $Z_{221}=\mathbf{0 . 6 4 1 9}$ & $Z_{321}=0.8663$ \\
\hline & & 5 & $(0.73 ; \underline{0.37} ; 2.95)$ & $(0.38 ; 0.19 ; 1.97)$ & $(0.93 ; 0.61 ; 3.17)$ \\
\hline & & & $Z_{122}=0.9218$ & $Z_{222}=0.8974$ & $Z_{322}=0.8042$ \\
\hline & & 6 & $(0.71 ; 0.36 ; 3.03)$ & $(0.37 ; 0.18 ; 1.99)$ & $(0.95 ; 0.62 ; 2.82)$ \\
\hline & & & $Z_{123}=0.9099$ & $Z_{223}=0.8730$ & $Z_{323}=\mathbf{0 . 7 3 2 2}$ \\
\hline \multirow{6}{*}{1} & \multirow{6}{*}{200} & 7 & $(0.61 ; 0.33 ; 2.56)$ & $(0.38 ; 0.17 ; 1.96)$ & $(0.84 ; 0.60 ; 4.92)$ \\
\hline & & & $Z_{131}=0.7972$ & $Z_{231}=0.8616$ & $Z_{331}=0.8814$ \\
\hline & & 8 & $(\underline{0.76} ; 0.36 ; 2.41)$ & $(0.37 ; 0.18 ; 1.41)$ & $(0.94 ; 0.75 ; 2.74)$ \\
\hline & & & $\overline{Z_{132}}=0.8824$ & $Z_{232}=0.6278$ & $Z_{332}=0.7672$ \\
\hline & & 9 & $(0.73 ; 0.36 ; 1.96)$ & $(0.37 ; 0.19 ; 1.84)$ & $(0.96 ; 0.78 ; 2.71)$ \\
\hline & & & $Z_{133}=0.8315$ & $Z_{233}=0.8739$ & $Z_{333}=0.8569$ \\
\hline
\end{tabular}

Remark 1. As an example, in the Table 2 for each maintenance regime there are only three rational configurations of avionic systems. The configurations, which are represented by indices $Z_{111}, Z_{122}, Z_{132}$, $Z_{211}$ and $Z_{331}$, have values of weight, power consumption or overall cost that exceed the maximum allowable values.

The obtained results allow determining:

1) the minimum values of indices of resources expenditure $Z_{k i}$ for $k$ system considering $i$ maintenance regime:

$$
\begin{array}{lll}
Z_{11}=0.8827, & Z_{21}=0.7757, & Z_{31}=0.7818, \\
Z_{12}=0.7943, & Z_{22}=0.6419, & Z_{32}=0.7322, \\
Z_{13}=0.7972, & Z_{23}=0.6278, & Z_{33}=0.7672 ;
\end{array}
$$

2) the minimum values of indices of resources expenditure $Z_{i}$ for avionics considering $i$ maintenance regime:

$$
Z_{1}=2.4403, \quad Z_{2}=2.1685, \quad Z_{3}=2.1923 ;
$$

3) the optimal configurations of avionic systems $Z_{2}$, which according to (14) has the smallest value of the sum of $Z_{k i}$ (Table 2);

4) the rational $\mathrm{MR}$ is the $2^{\text {nd }}$ maintenance regime.

Table 3. Calculated reliability of the unmanned aerial vehicle $T_{O P}=50$, hr.

\begin{tabular}{|c|c|c|c|c|c|c|}
\hline $\begin{array}{c}\text { Reliability } \\
\text { models }\end{array}$ & $\begin{array}{c}\text { Detection and } \\
\text { switching devices }\end{array}$ & $P_{F C S}(50)$ & $P_{C S}(50)$ & $P_{F M S}(50)$ & $P_{U A V}(50)$ & $\begin{array}{c}T_{O P}, \mathrm{hr} \\
\left(\text { for } P_{U A V}=0.93\right)\end{array}$ \\
\hline known & perfect & 0.98387 & 0.98401 & 0.98452 & 0.93408 & 51.2 \\
\hline offered & non-perfect & 0.96534 & 0.97148 & 0.97311 & 0.89584 & 37.9 \\
\hline
\end{tabular}


To compare the existed and proposed optimization techniques we calculated the reliability of designed UAV with identified optimal configurations of avionic systems (Fig. 6 and Table 3) using their well-known and developed reliability models [19].

Based on the obtained results we made the following conclusions:

1) the UAV reliability which is evaluated using the well-known reliability models with idealization of the DSD [19] satisfies the condition $P_{U A V}(t) \geqslant 0.93$ at the operation interval $T_{O P 1}=51.2 \mathrm{hr}$ $>T_{E C m i n}$. But the UAV reliability, which is calculated with the use of the proposed reliability models considering the effectiveness of non-perfect DSD, does not satisfy the above-stated condition $\left(T_{O P 2}=37.9 \mathrm{hr}<T_{E C \min }\right)$. The discrepancy in the results (Table 3 and Fig. 6 ) indicates a significant impact of the DSD effectiveness on the reliability of fault-tolerant units and respectively on reliability of avionics and unmanned aircraft;

2) application of the existed optimization techniques [14-17] that are based on the simplified reliability models leads to the decreasing validity of the design analysis results. It causes the irrational design decisions that pertain to reducing the amount of redundancy, selecting the less reliable elements. Consequently, the field reliability of the UAV avionics can be $5-10 \%$ lower than expected $[1,2,4,19]$;

3) use of the proposed optimization method, which is based on the improved decision model, enables increasing reliability and validity of determination of the optimal avionics structure. At the same time the developed technique allows ensuring required effectiveness and reliability with minimization of resources expenditure.

Validity of the results that are obtained with use of the proposed methodology is confirmed by application of the time-tested methods of complex systems' modeling, Markov method and multicriteria decision analysis methods. The results have clear physical interpretation and do not contradict the wellknown scientific theories. The outcomes of the reliability modeling are characterized by asymptotic agreement with results that were attained with application of the known models [19].

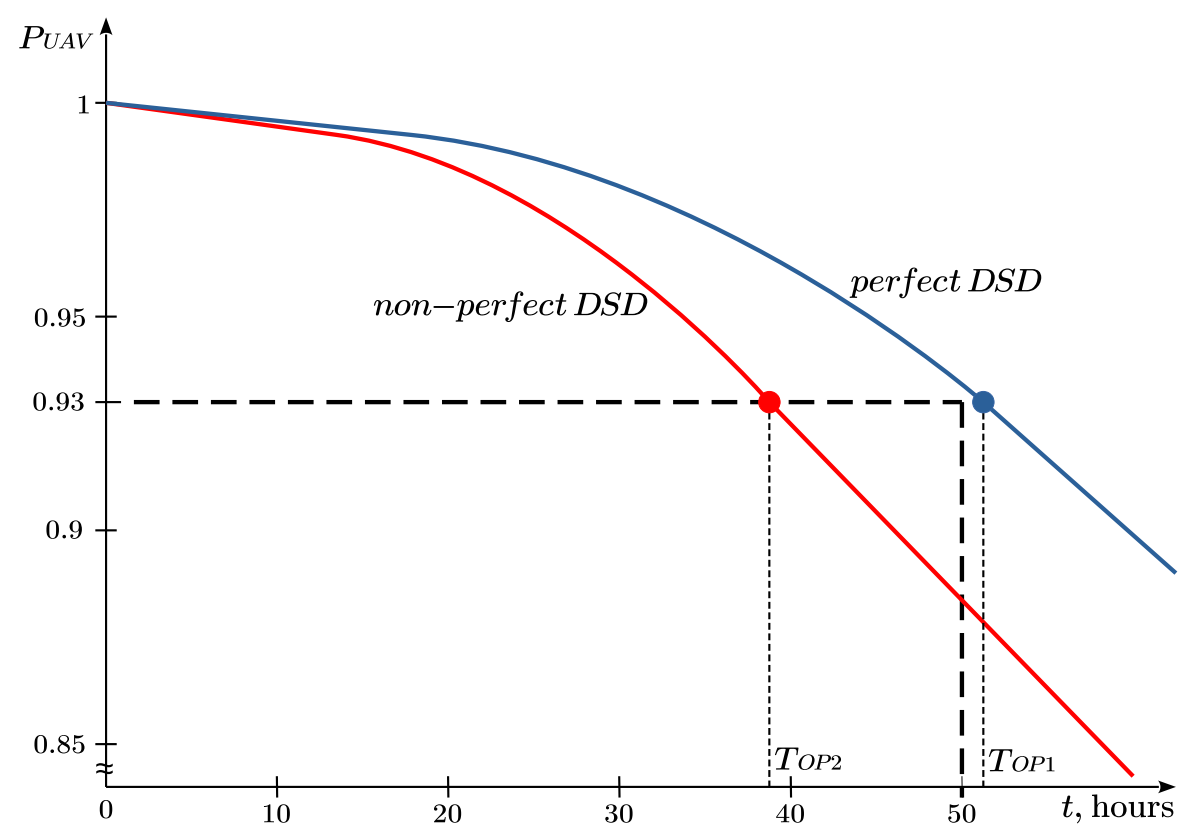

Fig. 6. Graphs of the unmanned aerial vehicle reliability (FTUs of avionics with perfect DSD (graph 1), FTUs with non-perfect DSD (graph 2)).

Reliability of the obtained results is confirmed by:

- developing formal decision model with high adequacy considering the most important factors that influence the UAV avionics design and increasing number of the utility attributes, using valid assumptions and limitations;

- using advanced reliability models of avionic systems that consider besides reliability parameters of main and standby elements of fault-tolerant units also effectiveness of non-perfect detection and switching devices [19];

- solving the optimization task with use of well-known scientific and methodical approaches, as well as proper input data, which are based on information from the field operation of UAVs [18]; 
- convergence of results from the theoretical research and flight experiments with testing UAVs "XUAV Talon EPO $1718 \mathrm{~mm}$ " [18]. One part of these aerial vehicles had a basic configuration and other drones were modernized by adding structural redundancy for avionic systems based on the analysis of their field reliability considering the least reliable elements. The experiments confirmed that increasing the reliability of modernized UAVs have improved their efficiency in performing air reconnaissance tasks but with deterioration of other quality indicators, particularly, their weight and cost have increased.

\section{Conclusions}

Thus, in this paper, the development and application of the method that can be implemented for optimizing the UAV avionics structure at the early design stages are described. The proposed approach is based on the additive multi-attribute utility function. The technique allows determining the optimal configurations of the avionic systems as well as rational maintenance activities ensuring the required UAV effectiveness and reliability, minimizing the expenditure of resources.

The proposed methodology is developed on the improved decision model that has a high degree of adequacy primarily by the increasing number of the utility attributes and using the advanced reliability models of avionic systems [19]. These reliability models consider the effectiveness parameters of nonperfect detection and switching devices of fault-tolerant units in addition to the reliability parameters of their main and standby elements. The developed optimization technique enables increasing the reliability and validity of design results.

The created algorithm and corresponding prototypes of specialized software for its implementation allow the decision-makers to solve the optimization task with a significant reduction of the time for performing the avionics design analysis and improving its quality. Since the developed technique is based on the reliability models of universal fault-tolerant units as well as on the optimality criterion of minimum technical and economic costs, it may be applied to determine the optimal structure of any complex system with hardware redundancy.

[1] 21st Century Unmanned Aerial Vehicles (UAV). Unmanned Aerial Vehicle Reliability Study. Office of the Secretary of Defense. OSD UAV Reliability Study Executive Summary. Pp. 9-26 (2010).

[2] Caswell G., Dodd E. Improving UAV Reliability. DfR Solutions. Pp. 1-5 (2014).

[3] Kuo W., Zuo M. J. Optimal Reliability Modeling: Principles and Applications. John Wiley \& Sons Inc. (2003).

[4] Reliability/Availability of Electrical \& Mechanical Systems for C4ISR Facilities. Department of the Army, TM 5-698-1. Pp. 14-18, 20-22, 27-34 (2003).

[5] Dubrova E. Fault tolerant design: an introduction. Department of Microelectronics and Information Technology Royal Institute of Technology Stockholm, Sweden. Kluwer Academic Publishers. Pp. 1-4, 14, 27-41, $27-55$ (2007).

[6] Zhangchun T., Zhenzhou L. Reliability based design optimization for the structure with fuzzy variables and uncertain but bounded variables. AIAA Journal of Aerospace Information. 1, 412-422 (2014).

[7] Singer J., Doerry N., Buckley M. What is set-based design? Naval Engineers Journal. 121 (4), 31-43 (2009).

[8] Jiménez A., Ríos-Insua S., Mateos A. A decision support system for multiattribute utility evaluation based on imprecise assignments. Decision Support Systems. 36 (1), 65-792 (2003).

[9] Bertoni M., Bertoni A., Isaksson O. Evoke: A value-driven concept selection method for early system design. Journal of Systems Science and Systems Engineering. 27 (1), 46-77 (2018).

[10] Bertoni M., Wall J., Bertoni A. Model Driven Decision Arena: an aerospace study. Proceedings of the DESIGN 2018 15th International Design Conference. Pp. 171-182 (2018).

[11] Bertoni A., Bertoni M. Supporting early stage set-based concurrent engineering with value driven design. Proceedings of the Design Society: International Conference on Engineering. 1 (1), 2367-2376 (2019).

Mathematical Modeling and Computing, Vol. 7, No. 2, pp. 373-388 (2020) 
[12] Parkinson A., Balling R., Hedengren J. Optimization Methods for Engineering Design. Applications and Theory. Brigham Young University (2013).

[13] Collopy P., Hollingsworth P. Value-driven design. Journal of aircraft. 48 (3), 749-759 (2011).

[14] Damp L. Multi-objective and multidisciplinary design optimisation of unmanned aerial vehicle systems using hierarchical asynchronous parallel multi-objective evolutionary algorithms. Masters of Engineering (Aeronautical) Research. Pp. 27-39 (2007).

[15] Gonzalez L., Srinivas K., Periaux J., Whitney E. J. Multidisciplinary Design Optimisation of Unmanned Aerial Vehicles (UAV) using Multi-Criteria Evolutionary Algorithms. 6th World Congresses of Structural and Multidisciplinary Optimization. Pp. 1-9 (2005).

[16] Johry A., Kapoor M. Unmanned Aerial Vehicle (UAV) Fault Tolerant Design. International Journal of Engineering Technology Science and Research. 3 (6), 1-6 (2016).

[17] Cheung J., Scanlan J., Wong J., Forrester J., Eres H., Collopy P., Hollingsworth P., Wiseall S., Briceno S. Application of value-driven design to commercial aeroengine systems. Journal of Aircraft. 49 (3), 688-702 (2012).

[18] Scientific Report on Experiment. Exploring ways to improve capabilities of unmanned aerial vehicles. National Army Academy, Lviv (2017), (in Ukrainian).

[19] Pashchuk Y., Salnyk Y., Volochiy B., Ozharevskyi V. Reliability-Oriented Approach for UAV Flight Control System Structural Optimization. Proceedings of the International Conference ICTERI CEUR-WS.org. Pp. 608-624 (2018).

[20] Unmanned Aircraft System (UAS) Maintenance Standard. NCATT. Fort Worth, TX 76136. 52 p. (2012).

[21] Petritoli E., Leccese F., Ciani L. Reliability and maintenance analysis of unmanned aerial vehicles, Sensors. 18 (9), 3171 (2018).

[22] Vollmerhausen R. H., Jacobs E. L., Driggers R. G. New metric for predicting target acquisition performance. Optical Engineering. 43 (11) (2004).

[23] Guidelines and methods for conducting the safety assessment process on civil airborne systems and equipment. Aerospace Recommended Practice (ARP4761). Pp. 4-151 (1996).

[24] System Design and Analysis Harmonization and Technology Update. Regulations and Policies. 14 CFR Part 25. Department of Transportation. Federal Aviation Administration. Pp. 9-28, 31-89 (2002).

[25] System safety analysis and assessment for part 23 airplanes. Advisory Circular. AC No: 23.1309-1E from 11/17 /2011. U.S. Department of Transportation. Federal Aviation Administration. Pp. 1-34 (2011).

[26] Druzhinin E., Kritsky D., Zakharchuk A. Features of a mass model for unmanned aerial vehicle. Information processing systems. 1 (108), 44-48 (2013), (in Russian).

[27] Krasilshchikov M., Sebryakov G. Modern information technologies in the problems of navigation and guidance of unmanned maneuverable aircraft. Moscow, FIZMATLIT (2017), (in Russian).

[28] Gutkin L. Optimization of Radio Electronic Systems in conjunction with performance indices. Moskow, Soviet Radio. Pp. 3-37 (1975), (in Russian).

[29] Bellman R. The Theory of Dynamic Programming. The Rand Corporation (1954).

[30] DSTU 3524-97 (GOST 27.205-97). Reliability of equipment. Design reliability assessment of complex systems. Kyiv. 27 p. (1999), (in Ukrainian).

[31] Petukhov B. Electric power supply of aircraft. Textbook. Leningrad (1960), (in Russian). 


\title{
Метод структурної оптимізації авіоніки безпілотного літального апарату
}

\author{
Пащук Ю. М. ${ }^{1}$, Сальник Ю. П. ${ }^{1}$, Пашковський В. В. ${ }^{1}$, \\ Заєць Я. Г. ${ }^{1}$, Міськів В.-М. В. ${ }^{2}$, Шкілюк О. П. ${ }^{2}$ \\ ${ }^{1}$ Начіональна академія сухопутних військ імені гетьмана Петра Сагайдачного, \\ вул. Героїв Майдану, 32, 79012, Львів, Україна \\ ${ }^{2}$ Національний університет "Львівсъка політехніка", \\ вул. С. Бандери, 12, 79013, Лъвів, Україна
}

У статті представлено підхід до визначення оптимальних конфігурацій систем авіоніки безпілотного літального апарату (БпЛА) на основі використання узагальненого критерію оптимальності у вигляді адитивної полілінійної функції корисності з узгодженням шкали вимірювання аргументів. Аргументи функції в інтегральній формі характеризують основні технічні та економічні показники якості систем обладнання, що відповідають вимогам до БпЛА. Методика оптимізації структури авіоніки БпЛА грунтується на удосконаленій формалізованій моделі розв'язання задачі оптимізації, що має високий ступінь адекватності через врахування багатомірної множини визначальних показників якості та застосування удосконалених надійнісних моделей систем бортового обладнання. Розроблені надійнісні моделі, на відміну від відомих, крім показників надійності основних та резервних елементів відмовостійких модулів, ураховують показники ефективності засобів контролю та перемикання. Використання запропонованої методики дає змогу підвищити достовірність визначення оптимальних конфігурацій систем бортового обладнання та раціонального режиму технічного обслуговування, що уможливлює забезпечення заданого рівня надійності та ефективності застосування БпЛА з мінімізацією техніко-економічних затрат.

Ключові слова: безпілотний літальний апарат, авіоніка, оптимізачія структури систем, надійність, надлишковість, технічне обслуговування. 